\title{
O Prognóstico da Insuficiência Cardíaca no Brasil: a Busca de Dados Confiáveis e Representativos
}

\author{
The Prognosis of Heart Failure in Brazil: the Search for Reliable and Representative Data
}

\author{
Luis E. Rohde \\ Porto Alegre, RS
}

Apesar dos inquestionáveis avanços terapêuticos alcançados nas últimas duas décadas, insuficiência cardíaca (IC) continua sendo responsável por elevada morbidade e mortalidade em todo mundo ${ }^{1}$. Embora estudos nacionais sejam escassos, e não necessariamente representativos de todo o país, dados pontuais sugerem que o impacto epidemiológico e funcional da IC no Brasil seja de magnitude similar aquela encontrada em outros países ${ }^{2}$. Neste contexto, o entendimento dos aspectos prognósticos da síndrome sempre foi motivo de intensa investigação científica ${ }^{3}$. Isto se baseia no conceito lógico, embora pouco comprovado, que o conhecimento da história natural e dos potenciais fatores de risco relacionado com sua morbi-letalidade seja fundamental para o estabelecimento de novas abordagens terapêuticas e para priorização de estratégias de tratamento comprovadamente benéficos. Dessa forma, a literatura científica está repleta de estudos observacionais de cunho prognóstico, alguns bem planejados e delineados, outros nem tanto, e que oferecem inúmeros preditores clínicos e laboratoriais de risco, presumivelmente de forma independente.

A compilação destas informações, entretanto, por vezes gera mais confusão do que esclarecimento para o cardiologista clínico que simplesmente busca identificar qual paciente terá de fato pior evolução clínica. Uma análise mais detalhada dos diversos estudos prognósticos nos demonstra resultados habitualmente não consensuais e, algumas vezes, até contraditórios ${ }^{4}$. As explicações para esta aparente inconsistência são múltiplas. Primeiramente, a complexidade fisiopatológica da síndrome e a profunda interrelação entre os diversos sistemas regulatórios permitem que inúmeras características clínicas e laboratoriais - em verdade, mais de cem preditores já foram relatados - tenham a capacidade de predizer risco quando analisados individualmente ${ }^{3,4}$. A determinação de quais destes fatores se associa de forma independente com prognóstico é tarefa complexa do ponto de vista estatístico, em parte pela intensa colinearidade entre as diferentes variáveis. Ainda mais, muitos estudos carecem de poder estatístico adequado, realizam análises retrospectivas de banco de dados incompletos ou pouco confiáveis, ficando limitados na seleção e identificação dos potenciais preditores de risco. Por fim, a análise retrospectiva de dados derivados de grandes ensaios clínicos, uma estraté-

Hospital de Clínicas de Porto Alegre - UFRGS

Endereço para correspondência: Luis E. Rohde - Hospital de Clínicas de Porto Alegre - Serviço de Cardiologia

Rua Ramiro Barcelos, 2350 - S/ 2060 - Cep 90003-035

Porto Alegre, RS - E-mail: lerhode@terra.com.br gia freqüente nesta área de investigação, muitas vezes não traduz de forma fiel a gravidade e as reais características dos pacientes que vemos na nossa prática clínica diária.

Nesta edição dos Arquivos Brasileiros de Cardiologia, Rassi e cols. apresentam dados prospectivos de uma coorte de 204 pacientes com IC atendidos na região metropolitana de Goiás, cidade no centro-oeste brasileiro, e que foram acompanhados por aproximadamente 4 anos ${ }^{5}$. A amostra em estudo foi cuidadosamente selecionada incorporando apenas pacientes com início recente dos sintomas e com disfunção ventricular sistólica documentada. Mas afinal, será que os achados de Rassi e cols. de fato acrescentam informações cientificamente relevantes em um cenário de investigação relativamente confuso, mas já repleto de avaliações similares?

Os méritos do estudo são de fato indubitáveis! A opção dos autores por avaliar apenas pacientes com início dos sintomas nas últimas 6 semanas e predominantemente referenciados pela rede pública de atendimento limita, pelo menos parcialmente, um dos principais vieses de estudos de sobrevida em IC: a incorporação de pacientes em diferentes estágios da história natural da doença. Com esta abordagem, os autores nos relatam sobrevida de 91\% e 70\% em 1 e 4 anos de acompanhamento, respectivamente. Estes dados se comparam de forma extremamente favorável com outros achados da literatura. Cowie e cols., em estudo similar que avaliou programas de atenção primária na Inglaterra, descrevem mortalidade significativamente pior para IC de diagnóstico recente, quando apenas $62 \%$ dos pacientes estavam vivos após um ano de seguimento ${ }^{6}$. Os resultados apresentados por Rassi e cols. talvez representem a primeira evidência consistente de meIhora prognóstica com o tratamento "moderno" da IC no Brasil, incorporando os benefícios clínicos do uso de inibidores da enzima de conversão da angiotensina, betabloqueadores, antagonistas da aldosterona e desfibriladores cardíacos. 0 estudo, entretanto, não deixa claro o percentual de utilização de cada uma dessas intervenções, o que poderia esclarecer em parte as razões do prognóstico tão benigno. Deve-se ressaltar também que os pacientes foram aparentemente manejados em clínica especializada, possivelmente multidisciplinar, por cardiologistas com experiência no manejo da IC. Este ambiente certamente não reproduz a realidade de tratamento da maioria dos pacientes acometidos por IC no Brasil.

Dentre os preditores prognósticos encontrados nesta análise, certamente se destaca o impressionante risco associado a etiologia chagásica. Os investigadores demonstram que a presença desta etiologia implica em incremento de 10 vezes no risco de morte. Embora os intervalos de confiança desta associação sejam amplos, este achado, além de sua magnitude, merece reflexão profun- 
da. A possibilidade que diferentes etiologias possam ter impacto prognóstico vem sendo explorada por inúmeros investigadores. Embora os achados não sejam consensuais, o corpo das evidências sugere que pacientes com etiologia isquêmica tenham curso desfavorável em relação aqueles com miocardiopatia idiopática ${ }^{3}$. A sobrevida em pacientes com miocardiopatia chagásica também parece cursar de forma adversa. Mady e cols. relatam taxas de mortalidade em um ano de apenas $66 \%$ em pacientes jovens com IC de origem chagásica ${ }^{7}$. De forma similar, Bestetti e cols. demonstram mortalidade quase 4 vezes maior para pacientes chagásicos quando comparados aos não chagásicos ${ }^{8}$. Nenhum outro estudo, entretanto, demonstrou tamanha magnitude de associação da origem chagásica da miocardiopatia com mortalidade. É necessário que se esclareça porque em uma coorte de pacientes com IC com prognóstico relativamente benigno, aqueles de origem chagásica permanecem com evolução tão desfavorável. É plausível especular que as estratégias de tratamento derivadas de ensaios clínicos internacionais que avaliam predominantemente pacientes com etiologia isquêmica, hipertensiva e idiopática não se traduzam em benefícios clínicos substanciais em pacientes de etiologia chagásica. Nesse sentido, teria sido esclarecedor se os investigadores tivessem descrito de forma detalhada as características clínicas e de tratamento estratificadas por etiologia, bem como a forma de morte dos pacientes em estudo.

Outro preditor de risco de mortalidade identificado por Rassi e cols. que merece discussão é a presença de $3^{a}$ bulha. Este achado clínico está associado a pressões de enchimento ventricular elevadas ${ }^{9} \mathrm{e}$ já foi descrito como marcador prognóstico independente em análise retrospectiva do ensaio clínico SOLVD ${ }^{10}$. Os mecanismos pelos quais sinais e sintomas de IC predizem mortalidade não estão completamente esclarecidos, mas podem estar relacionados ao desbalanço hemodinâmico associado com congestão clínica. Elevação de pressões de enchimento de cavidades esquerdas e direitas já foi associada com prognóstico reservado na IC crônica ${ }^{11}$. A indução de apoptose de miócitos e ativação do sistema simpático podem ser implicados como mecanismos plausíveis pelos quais congestão poderia estar associada com pior evolução clíni$\mathrm{ca}^{12}$. As evidências geradas por estes estudos, incluindo o acha- do de Rassi e cols. em pacientes com início recente dos sintomas, reforçam a necessidade para treinamento contínuo da equipe médica para realização de exames clínicos detalhados, confiáveis e reprodutíveis.

As potenciais explicações porque outros fatores de risco consistentemente descritos em estudos prognósticos prévios ${ }^{3,4}$ não emergiram como preditores de mortalidade - como idade, hiponatremia e função ventricular - também merecem consideração. Embora a seleção de pacientes com início recente dos sintomas possa explicar em parte a ausência de associação destas características clínicas, deve-se considerar que o número relativamente pequeno de pacientes pode ter conferido poder estatístico limitado ao presente estudo. Em especial, causa surpresa que fração de ejeção de ventrículo esquerdo não tenha se mantido no modelo final de predição de risco, uma vez que parâmetros de função ventricular sistólica são sistematicamente relatados - de fato, quase de forma unânime como preditores independentes em estudos prognósticos em IC 3,4.

Existe consenso entre os pesquisadores que o estudo de informações prognósticas na IC é essencial, não só pelas potenciais implicações terapêuticas, mas também pela necessidade de informarmos de forma aberta, construtiva e clara aos nossos pacientes os riscos de sua doença. Se os médicos falharem nesta tarefa, estarão negando aos seus doentes a oportunidade de realizarem escoIhas melhor embasadas sobre seu tratamento. Uma avaliação prognóstica imprecisa pode implicar em decisões terapêuticas distorcidas, umas vez que pacientes necessitam de um entendimento detalhado do seu prognóstico para mudar suas preferências de tratamento ${ }^{13}$. Em particular, a escolha entre "qualidade de vida" e "quantidade de vida" é aspecto relevante no estabelecimento de estratégias terapêuticas individualizadas e que necessita ampla e detalhada discussão de informações prognósticas. Desta forma, a iniciativa dos investigadores do presente estudo precisa ser grandemente congratulada, pois carecemos de dados robustos e confiáveis sobre a epidemiologia da IC no Brasil. Também parece imperativo que pesquisadores brasileiros desenvolvam uma rede colaborativa, isenta e multi-institucional de coleta de dados para a realização de avaliações representativas e precisas da epidemiologia da IC no Brasil.

\section{Referências}

1. American Heart Association. 2005 Heart Disease and Stroke Statistical update. Disponível no endereço eletrônico: http://www.americanheart.org/statistics. Accesso em 02/02/2005.

2. Rohde LE, Clausell N, Ribeiro JP et al. Health Outcomes in Decompensated Congestive Heart Failure: A Comparison of Tertiary Hospitals in Brazil and United States. Intern J Cardiol 2005 (no prelo). Publicado on line em 26/08/2004. Disponível no endereço eletrônico: http://www.sciencedirect.com/science/journal/01675273.

3. Villacorta H, Mesquita ET. Fatores prognósticos em portadores de insuficiência cardíaca congestiva. Arq Bras Cardiol 1999;72: 343-52.

4. Cowburn PJ, Cleland JGF, Coats AJS, et al. Risk stratification in chronic heart failure. Eur Heart J 1998; 19: 696-710.

5. Rassi S, Barretto ACP, Porto CC, Pereira CR, Calaça BW, Rassi D. Sobrevida e fatores prognósticos na insuficiência cardíaca sistólica com início recente dos sintomas. Arq Bras Cardiol 2005.

6. Cowie MR, Wood DA, Coats AJ et al. Survival of patients with a new diagnosis of heart faiure: a population based study. Heart 2000; 83: 505-10.

7. Mady C, Cardoso RH, Barreto AC, da Luz PL, Bellotti G, Pileggi F. Survival and pre- dictors of survival in patients with congestive heart failure due to Chagas' cardiomyopaty. Circulation 1994; 90: 3098-102.

8. Bestetti RB, Muccillo G. Clinical course of Chagas'heart disease: a comparison with dilated cardiomyopathy. Int J Cardiol 1997; 60: 187-93.

9. Rohde LE, Silva Neto LB, Goldraich L et al. Reliability and prognostic value of traditional signs and symptoms in outpatients with congestive heart failure. Can J Cardiol 2004; 20: 697-702.

10. Drazner MD, Rame JE, Stevenson LW, Dries DL. Prognostic importance of elevated jugular venous pressure and a third heart sound in patients with heart failure. $\mathrm{N}$ Engl J Med 2001; 345: 574-81.

11. Morley D, Brozena SC. Assessing risk by hemodynamic profile in patients awaiting cardiac transplantation. Am J Cardiol 1994; 73: 379-83.

12. Leri A, Claudio PP, Li Q et al. Stretch-mediated release of angiotensin II induces myocite apoptosis by activating p53 that enhances the local renin-angiotensin system and decreases the Bcl-2-to-Bax protein ratio in the cell. J Clin Invest 1998; 101: 1326-42.

13. Cowie MR. Estimating prognosis in heart failure: time for a better approach. Heart 2003; 89: 587-8. 